\title{
Q. Sertorio, personaje literario: creación, reelaboración y recepción
}

\author{
Q. Sertorius as a Literary Character: Crafting, Reworking and \\ Reception
}

\author{
DAVID GARCÍA DOMÍNGUEZ \\ Universidad Autónoma de Madrid \\ david.garciadominguez@estudiante.uam.es
}

Resumen: Las fuentes literarias disponibles ofrecen tratamientos muy contrastados sobre el personaje de Q. Sertorio. Aunque tradicionalmente se ha considerado esta circunstancia como el reflejo de la existencia de dos "tradiciones" al respecto, completamente aisladas entre sí, cada vez se hace más evidente que esta postura es insostenible. Convendría, en su lugar, individualizar cada iteración literaria de Sertorio dentro de las coordenadas temporales y discursivas que le son propias, enfocando los sucesivos retratos del personaje como los frutos de las concepciones ideológicas, históricas y literarias de sus respectivos autores. De este modo, se llegará a una valoración más equilibrada del significado y utilidad relativa de cada texto. A su vez, la huida del positivismo que generalmente ha presidido el estudio de esta cuestión permitirá evaluar la recepción del personaje y proponer vías de interpretación más fructíferas que la mera "búsqueda del verdadero Sertorio".

Palabras clave: Sertorio, fuentes literarias, tradición clásica, Salustio, Livio.

Abstract: Q. Sertorius's character has been object of some unequal treatments in the remaining literary sources. Although this circumstance has traditionally been considered as the effect of the existence of two isolated "traditions", it becomes increasingly clearer that we can't hold this view anymore. It would be advisable, however, to individualize each literary iteration of Sertorius within its temporal and discursive coordinates. This methodology will lead to more balanced assessments of the significance and relative utility of each extant text. We also think that fleeing from the positivism generally presiding the study of this matter will allow us to evaluate the reception of the character, and, more importantly, to propose more significant approaches than the mere "search for the real Sertorius".

Keywords: Sertorius, literary sources, classical tradition, Sallust, Livy.

Recibido: 31 de octubre de 2017; aceptado: 15 de abril de 2018; publicado: 27 de septiembre de 2018.

Revista Historia Autónoma, 13 (2018), pp. 55-70

DOI: https://doi.org/10.15366/rha2018.13.003 
Introducción ${ }^{1}$

El tiempo, y con él la permanente renovación del discurso histórico imaginado a la luz del presente vivido, han ido acumulando sobre el personaje de Quinto Sertorio (122-72 a. C.) una aplastante cantidad de bibliografía que, en su sorprendente disparidad, resulta sumamente difícil de estudiar. La creación y recreación del personaje, particularmente intensa entre los siglos I a. C. y v d. C., pareció quedar en suspenso hasta que en pleno s. XVII fuera retomada por Corneille, en cuyas manos el episodio sertoriano quedaría convertido en dramático escenario sobre el que desplegar una síntesis de los problemas históricos y políticos que preocupaban en la Francia de su época. Admirado por Niebuhr y Mommsen², las tensiones de la Europa de los años 20 del siglo pasado propiciarían la producción de nuevas relecturas del personaje, siempre adaptable, siempre camaleónico ${ }^{3}$.

Verdaderamente, estamos ante un problema multifacético, alimentado por la pronta conversión del episodio sertoriano en material de reflexión política cuyas implicaciones superan su marco inmediato, pero también por la propia actitud del personaje y un probable interés personal en proyectar una determinada imagen de sí mismo, una imagen lindante con la leyenda ${ }^{4}$ que desnaturalizó rápidamente al hombre para colocarlo precisamente en el plano de los mitos historiográficos. El material, por tanto, resultaba atractivo, cuajado como está de episodios dramáticos, simbólicos, sobrepasando en ocasiones la frontera de lo mágico. Pero no solo en las posibilidades literarias e interpretativas del material reposa la explicación del prolífico destino literario de Sertorio: posiblemente, las líneas maestras en que sustentó su propaganda ${ }^{5}$, y su propio lugar en el devenir general de la República romana tardía hacia

\footnotetext{
${ }^{1}$ Nos gustaría agradecer al Profesor D. Eduardo Sánchez Moreno su revisión de este manuscrito, así como sus esclarecedores comentarios y aportaciones. Por supuesto, cualquier error nos pertenece por completo.

${ }^{2}$ Mommsen, Theodor, Historia de Roma. Vol. VII, Madrid, Turner, 1983, pp. 30-36 y 42-54; Niebuhr, Berthold Georg, The History of Rome, from the earliest times to the fall of the Western Empire. Vol. II, Londres, Taylor, Walton \& Maberly, 1849, pp. 374 y 399-404. Ambos insisten en la "humanidad" de su carácter, en su "nobleza", y lo sitúan moralmente por encima del resto de hombres de su tiempo. Para Niebuhr, "[...] is one of the best Romans of those times; he was noble-minded, open, humane, free from the narrow prejudices of his countrymen [...]" (Niebuhr, Berthold Georg, The History of Rome... op. cit., p. 374); mientras que Mommsen descubre en él "un corazón franco y buenos sentimientos hasta rayar casi en la debilidad" (Mommsen, Theodor, Historia de Roma... op. cit., p. 30, vid. también el elogio fúnebre que le dedica a su muerte en p. 54).

${ }^{3}$ Las fuentes sobre Q. Sertorio se hallan recogidas en Schulten, Adolf, Fontes Hispaniae Antiquae IV. Las guerras de 154-72 a. de J.C. Edición y comentario por Adolfo Schulten, Barcelona, Librería Bosch, 1937. Su visión sobre la validez y prelación de las mismas, sin embargo, ha sido ampliamente contestada: Neira Jiménez, María Luz, "Aportación al estudio de las fuentes antiguas sobre Sertorio", en Gerion, 4 (1986), pp. 189-211. Sobre el Sertorio neoclásico, $c f$. Imbert, Cristophe, "Sertorius, exemplum politique et figure littéraire au seuil de l'âge classique", en Pallas, 60 (2002), pp. 133-145, especialmente pp. 136-141. Centrado en la historiografía sertoriana del siglo pasado, Plácido Suárez, Domingo, "La historiografía española sobre Sertorio", en Arce Martínez, Javier y Ricardo Olmos Romera (coords.), Historiografía de la Arqueología y de la Historia Antigua en España (siglos XVIII-XIX). Actas del Congreso Internacional, Madrid, Ministerio de Cultura-Instituto de Conservación y Restauración de Bienes Culturales, 1991, pp. 227-228.

${ }^{4}$ Pailler, Jean Marie, "Fabuleux Sertorius", en Dialogues d'histoire ancienne, vol. 26, 2 (2000), pp. 45-61; Moret, Pierre y Jean Marie Pailler, "Mythes ibériques et mythes romains dans la figure de Sertorius", en Pallas, 60 (2002), pp. 125-131.

5Beltrán Llorís, Francisco, "La pietas de Sertorio”, en Gerion, 8 (1990), pp. 215-226; Manchón Zorrilla, Alejandro, “«Pietas erga patriam»: la propaganda política de Quinto Sertorio y su trascendencia en las fuentes literarias
} 
el poder autocrático ${ }^{6}$, explican el impulso que en época imperial parece haber espoleado a los historiadores (y convendría matizar lo que se entiende por tal durante la Antigüedad grecorromana) a reflexionar sobre la guerra de Sertorio. Siquiera como jalón en la carrera de Cn. Pompeyo Magno, era necesario producir una imagen crecientemente simplificada de un carácter contradictorio. El destino del propio Sertorio, muerto en una conjura de sus allegados y nunca derrotado en batalla, supone un anticlimático final, dotado de esa épica crepuscular que eleva a sus protagonistas a la condición de iconos.

Es esta compleja y abundante herencia historiográfica la que justifica que volvamos una vez más sobre el ya manido tema de las fuentes escritas existentes sobre Q. Sertorio. Si la prelación de estas se halla relativamente bien establecida, aún cabe reflexionar sobre el modo en que la imagen de Sertorio, sus actividades y el entorno humano en que estas tienen lugar, se ven alteradas con cada una de sus iteraciones literarias. Creemos que no se ha esclarecido con suficiente rotundidad la influencia que el universo intelectual de cada autor clásico ha podido ejercer sobre su postura ante Sertorio y, consecuentemente, sobre la valoración y recreación de su época y carácter. Nuestro interés reside ante todo en deconstruir el discurso de aquellos autores (Diodoro Sículo, Salustio, Tito Livio y sus “epitomistas", Valerio Máximo, Veleyo Patérculo, Plutarco y Apiano) que escribieron relatos más o menos extensos al respecto, autores que debieron adoptar una postura ideológica determinada ante los hechos que narraban, prestando una atención marginal a las noticias puntuales o de cariz descriptivo (vid. Fig. 1). Han de quedar así al descubierto los mimbres con que se urdió cada retrato del de Nursia, un punto de partida fundamental para comprender exactamente qué podemos esperar de cada uno y en qué medida puede resultar engañoso a la hora de producir una valoración de conjunto del bellum Sertorianum.

Posteriormente, revisaremos con brevedad la evolución reciente de los estudios sertorianos, en cuya nómina obran ya algunos trabajos que, si bien desfasados en lo metodológico, son vitales para comprender la construcción de un personaje histórico complejo. Significativamente, el recorrido culmina con una brevísima referencia a aquellas miradas modernas que encontramos especialmente valiosas o innovadoras: caracterizadas por ampliar su foco o por intentar trascender el anecdotismo y la distorsión del enfoque exógeno, suponen importantes rupturas respecto a la herencia que nos hemos propuesto examinar.

Nuestro objetivo no es, en absoluto, poner en cuestión el valor de la información literaria: más bien al contrario, consideramos que el irreemplazable valor de las fuentes escritas exige un uso responsable y consciente de sus aportaciones. En este sentido, nuestro esfuerzo debe ser no tanto sustituirlas por testimonios alternativos, como indagar en el discurso que nos transmiten e intentar aplicar las herramientas de exégesis con las que la investigación moderna se ha ido dotando con el objetivo de acceder a una lectura menos parcial y más introspectiva y contextual

clásicas”, en Bolskan, 25 (2014), pp. 161-172.

${ }^{6}$ Plácido Suárez, Domingo, “Sertorio", en Studia Historica. Historia Antigua, 7 (1989), pp. 97-104. 
de las informaciones sobre el significado general del episodio sertoriano y los objetivos de los colectivos implicados en él.

Una última precisión antes de lanzarnos sobre el tema apuntado. La práctica totalidad de los autores clásicos estructuran sus obras en torno a una asunción de partida: la de que los indígenas que rodean a Sertorio eran "una gran banda de ladrones" (Plut. Sert. 14, 1) antes de la intervención, digamos "civilizadora", de nuestro hombre. Convendría considerar, si nuestro objetivo es poner de relieve las distorsiones que cada autor, consciente o inconscientemente, introduce en su tratamiento del tiempo sertoriano, que todos ellos comparten una visión estereotipada de los hispanos, sobre cuya imagen pesaba una serie tópicos etnográficos que los hacían tan "furiosos" como "salvajes". Estos estereotipos condicionan, a su vez, la imagen que las fuentes nos trasladan de quien, durante un tiempo convulso y agitado, vino a convertirse en su caudillo: es esta la primera de las explicaciones que debemos contemplar a la hora de valorar el complejo y contradictorio tratamiento histórico de que ha sido objeto la figura de Quinto Sertorio. Desde el mismo momento en que nuestras fuentes, en un ejercicio de galopante etnocentrismo, no comprenden los discursos de poder locales o los desprecian como ajenos por su condición de bárbaros, todas las acciones de Sertorio quedan distorsionadas, descontextualizadas y reducidas al absurdo. Antes de valorar individualmente cada fuente, hemos de comprender que los informes en ellas contenidas carecen de una metodología equiparable a la de la antropología moderna y, consecuentemente, sustituyen de forma perniciosa la perspectiva del observado por la del observador?

\section{Fuentes y tradición historiográfica sobre Q. Sertorio, o la vida tras la muerte de un héroe popular}

Al menos desde la publicación de la influyente obra que Adolf Schulten dedicó a Q. Sertorio, se ha venido convirtiendo en un lugar común para la investigación el reconocer tanto el desigual valor de las informaciones que las fuentes nos ofrecen al respecto del sabino, como la existencia de dos supuestas tradiciones escritas prácticamente aisladas entre sí y opuestas en su juicio sobre el bellum Sertorianum ${ }^{8}$. La postura tradicional ha venido considerando, en este sentido, que Salustio y Livio se hallan, respectivamente, en el origen primigenio de las

\footnotetext{
${ }^{7}$ Son fundamentales en este sentido las reflexiones contenidas en García Quintela, Marco Virgilio, Mitología y mitos de la Hispania prerromana III, Madrid, Akal, 1999, pp. 37-51, sobre la "estética de la percepción" y sus limitaciones a la hora de estudiar la alteridad de las sociedades clásicas. Pretendemos un conocimiento ajustado a lo que él llama "conocimiento excéntrico" (para una definición, vid. p. 30). Vid. también Aguilera Durán, Tomás, "Una visión historiográfica alternativa: la deconstrucción del estereotipo del bárbaro prerromano", en Antesteria, 1 (2012), pp. 543-555.

${ }^{8}$ Schulten, Adolf, Sertorio, Sevilla, Renacimiento, 2013; sobre su visión de las fuentes clásicas, vid. pp. 49-63.
} 
versiones favorable y adversa a Sertorio. Por supuesto, a esta concepción de partida seguía un inevitable esfuerzo por adscribir cada obra disponible a una de las dos ramas descritas, cuya evidente falta de acuerdo (tornándose en ocasiones en total oposición) exigía al investigador una toma de postura que, siendo prácticamente un acto de fe y privilegiando las noticias de cariz encomiástico sobre las de tintes críticos o viceversa, no hacía sino forzar más allá de lo razonable la evidencia para "fabricar sertorios" tan artificiales y sesgados como los presentes en las fuentes antiguas. Este esquema interpretativo, marcado por el positivismo inherente a la pretensión de rescatar al "verdadero Sertorio" y por la concepción en exceso rígida de la relación entre los clásicos conservados, ha impedido la superación de los prejuicios y la emergencia de juicios históricos imparciales y constructivos.

No obstante, la aceptación del esquema schulteniano se halla en franca decadencia desde que María Luz Neira replanteara el problema en 1986, para concluir que las noticias disponibles no siempre habían sido adscritas adecuadamente a cada una de las corrientes anteriormente mencionadas y, más importante aún, que muchos autores parecían haber bebido de tradiciones variadas para elaborar sus propias obras ${ }^{10}$ [Fig. 1]. Se desdibujaba así un cuadro en exceso simplista y que había conducido a dividir de forma estricta nuestras informaciones, ya "filosertorianas", ya "antisertorianas", derivando en visiones estériles e igualmente maniqueas del de Nursia ${ }^{11}$.

Esta Quellenforschung, este estudio de fuentes, ha creado con sus valiosas conclusiones unas bases sólidas que permiten adentrarnos en el problema desde un punto de vista diferente, centrado en la consideración de los aportes personales añadidos por cada autor a la traditio recibida de sus predecesores. Obviamente, estas aportaciones suponen siempre una recreación, y en la medida en que esta depende del discurso social en que fueron concebidas tanto como de la percepción personal del autor de lo que supone el estudio del pasado, estamos ante un problema básicamente historiográfico.

\footnotetext{
${ }^{9}$ Palti, Elías José, "Pensar históricamente en una era postsecular. O del fin de los historiadores después del fin de la Historia”, en Sánchez León, Pablo y Jesús Izquierdo Martín (eds.), El fin de los historiadores, Madrid, Siglo XXI, 2008, pp. 32-35; Fernández Martínez, Víctor Manuel, "Pero, ¿tiene alguien razón? El problema de la objetividad y la crisis postmoderna en Historia y Arqueología”, en Cardete del Olmo, María Cruz (ed.), La Antigüedad y sus mitos. Narrativas históricas irreverentes, Madrid, Siglo XXI, 2010, pp. 169-174.

${ }^{10}$ Neira Jiménez, María Luz: “Aportación al estudio...” op. cit., pp. 195, 196-198, 199-200. Sus reflexiones han tenido una repercusión singular en la producción científica sobre Sertorio en nuestro idioma: $c f$. Plácido Suárez, Domingo, "Sertorio..." op cit.; Rodríguez Horrillo, Miguel Ángel, "Plutarco transmisor de Salustio: la Vida de Sertorio 10.5-7", en Candau Morón, José María et al. (dirs.), Plutarco transmisor. Actas del X Simposio Internacional de la Sociedad Española de Plutarquistas, Sevilla, Publicaciones de la Universidad de Sevilla, 2011, pp. 267-275; Manchón Zorrilla, Alejandro, "Pietas erga patriam..." op. cit.; o Salinas de Frías, Manuel, "Reflexiones sobre la guerra de Sertorio en la Hispania Citerior y sus fuentes literarias", en Sala Sellés, Feliciana y Jesús Moratalla Jávega (eds.), Las guerras civiles romanas en Hispania. Una revisión histórica desde la Contestania, Alicante, Publicacions i Edicions de la Universitat d'Alacant, 2014, pp. 23-33.

${ }^{11}$ Podríamos invocar como paradigmáticos de dichas visiones los sertorios del ya mencionado Adolf Schulten (véase el auténtico panegírico que cierra su monografía: Schulten, Adolf, Sertorius ... op. cit., pp. 263-272) y, en franca oposición, el de Helmut Berve: Berve, Helmut, "Sertorius", en Hermes, 64 (1929), pp. 199-227.
} 
Figura 1: Prelación de las fuentes clásicas que contienen informaciones sobre Q. Sertorio.

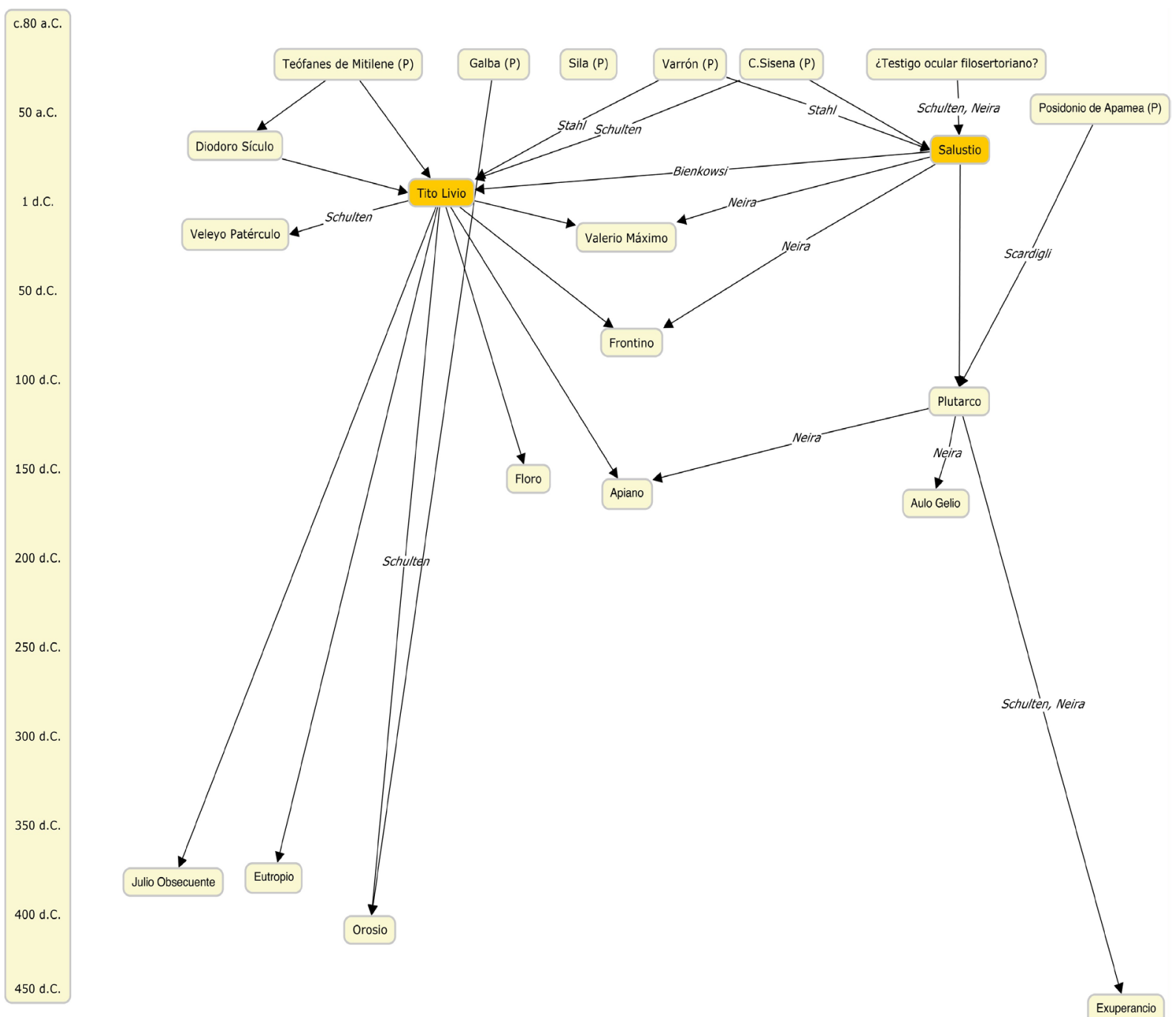

Notas: $(P)$ tuente perdida pero mencionada o conocida por otros autores clásicos. Cabe advertir que las relaciones expresadas manifiestan "conocimiento", no necesariamente comunidad de interpretación; por ejemplo, Salustio menciona a Varrón, pero habida cuenta de las posturas políticas de ambos, ha debido emplear su obra como elemento de contraste. No se han incluido las fuentes que transmiten noticias aisladas de desigual valor y que, debido a su brevedad o naturaleza, no pueden adscribirse con seguridad, a ninguna de las tradiciones escritas (Cicerón, César, Estrabón, Plinio el Viejo, Plinio el Joven, Dión Casio, Amiano Marcelino).

Fuente: elaboración propia.

Las ideologías subyacentes a las diversas producciones literarias que hemos de considerar deberían enfocarse desde la cautela. El simplismo, el pretender que cabe desnudar cada estampa de Sertorio hasta dejar a la vista un núcleo netamente favorable o adverso, es reducir a los autores clásicos al infantilismo y a la Historia a una ligereza carente de rigor: la realidad parece mucho más compleja. Así, como aspiramos a hacer evidente, es ilusorio esperar de Salustio una presentación totalmente favorable de "su héroe", pues su opinión no es ni mucho menos tan 
neta como el juicio histórico ha querido hacer ver ${ }^{12}$; de igual modo, Livio no es ni remotamente tan hostil a Sertorio como Diodoro y Apiano, cuyos relatos son singularmente denigrantes ${ }^{13}$, coincidiendo en el fundamental detalle de crear un nexo causal entre el comportamiento tiránico del popular y su asesinato.

Llegamos así al primer retrato de nuestro hombre en que nos gustaría detenernos. La opinión de Diodoro (¿?- c. 36 a. C.), que nos sale al paso en primer lugar desde un punto de vista cronológico, es interesante a pesar de su brevedad (Diod. XXXVII, 22 $\mathrm{a}^{14}$ ) por los aspectos en que centra lo que a todas luces pretende ser una descalificación difamatoria. A tal efecto, se critica su incapacidad para ejercer el liderazgo sobre sus aliados indígenas ("O

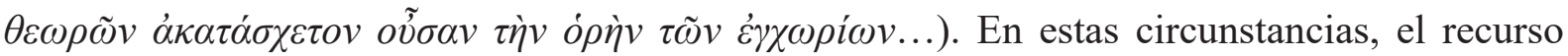
a la violencia habría sido el único modo de sostenerse "de manera odiosa" ( $\pi \iota \kappa \rho \tilde{\omega} \varsigma)$ usando la fuerza. Los motivos que finalmente le ganaron "el odio del pueblo" y el complot de sus allegados que terminó por conducir a su asesinato habrían sido la avaricia, la retención de los sueldos ( $\mu \iota \sigma \theta о \varphi о \rho i ́ \alpha \varsigma)$ de las tropas, un comportamiento autocrático en la administración de justicia, y la incapacidad para mostrar cercanía a sus amigos ( $\varphi \imath \lambda \alpha \nu \theta \rho \omega \pi i \alpha \varsigma)$ en los banquetes. Esta cascada de acusaciones se corresponde directamente con las exigencias que pesarían sobre los hombros de un monarca helenístico: liderazgo carismático, generosa (y exitosa) redistribución y virtuosa limitación del poder propio, en teoría ilimitado y en la práctica contrapesado por los equilibrios áulicos ${ }^{15}$. Tanto por sus propios intereses personales como por su concepción historiográfica, en que Roma prolonga y hereda los logros de la civilización helena $^{16}$, Diodoro juega con unos parámetros ideológicos en que la legitimidad del monarca reposa sobre su capacidad para someterse a los límites de la moralidad y la virtud, dejando de lado sus impulsos menos nobles. Es posible, por lo demás, que Diodoro haya empleado como fuente básica para tratar los asuntos posteriores a 146 al estoico Posidonio, lo que no haría sino añadir una razón más por la que su Sertorio presenta una morfología tan furiosamente helenística ${ }^{17}$. Charles Muntz considera probable que fuera precisamente el potencial polémico

\footnotetext{
${ }^{12}$ Konrad, Christoph Frederick, Plutarch's Sertorius. A historical commentary, Chapel Hill, University of North Carolina Press, 1994, p. XLIV: "[...] caution is advised. We must not imagine Sallust's treatment of Sertorius as an uncritical eulogy, idealized though it was". Aunque, como veremos, no compartimos completamente sus conclusiones, en este sentido es fundamental Rodríguez Horrillo, Miguel Ángel, "Plutarco transmisor de Salustio..." op. cit., subrayando la mediación de Plutarco a la hora de convertir el complejo personaje salustiano en una brillante personificación de la virtud domeñada por la fortuna adversa.

${ }^{13}$ Neira Jiménez, María Luz, “Aportación al estudio...” op. cit., pp. 192-193, para una reconsideración de la importancia de Diod. fr. 37. 22a.

${ }^{14}$ El fragmento se numera convencionalmente de este modo por la fuerza de la costumbre y el peso de la edición de Dindorf en la Bibliotheca Teubneriana (1842-1844), que a raíz de un curioso error tipográfico, fue colocado en un lugar erróneo desde un punto de vista cronológico. El lugar que realmente le corresponde es otro, en concreto, a continuación de los libros XXXVIII/XXXIX. Cf. Walton, Francis Redding, "Notes on Diodorus", en The American Journal of Philology, vol. 77, 4 (1956), p. 412. DOI: https://doi.org/10.2307/291867.

${ }^{15}$ Eckstein, Arthur M., "Hellenistic Monarchy in Theory and Practice", en Balot, Ryan K. (ed.), A companion to Greek and Roman political thought, Malden, Chichester y Oxford, Wiley-Blackwell, 2009, pp. 247-265. DOI: https://doi.org/10.1002/9781444310344.ch16. Ver especialmente p. 250 sobre la importancia y peso de los "amigos" (cortesanos) del rey y pp. 253-255 sobre la formulación ideal de las cualidades del monarca helenístico. ${ }^{16}$ La perspectiva griega de la historia universal de Diodoro: Martínez Pinna, Jorge, "Diodoro Sículo y los reyes de Roma”, en Gerión, vol. 29, 1 (2011), pp. 107-121, especialmente pp. 109-110.

${ }^{17}$ Shipley, Graham, El mundo griego después de Alejandro, 323-30 a. C., Barcelona, Crítica, 2001, pp. 34-35.
} 
que, en la época del advenimiento de Octaviano, acumulaba su visión limitada de la monarquía lo que refrenó la publicación de la totalidad de la Biblioteca Histórica en vida de Diodoro ${ }^{18}$. En tal caso, tendríamos una explicación coherente para comprender la escasa influencia posterior del Sertorio del historiador sículo; de cuyo retrato solamente sobrevivirá, convertida en tópico, la idea de la crudelitas Sertorii, desprovista sin embargo del contenido de crítica política que podría haber tenido originalmente.

Todo lo contrario ocurre con el texto que examinaremos inmediatamente a continuación. En nuestra opinión, con todas las dificultades que su estado fragmentario comporta, las Historias de Salustio (86-34 a. C.) deben ser consideradas el puntal fundamental de todo estudio de fuentes sobre Sertorio. Esto es así no tanto por su situación presente, reducida a la antedicha fragmentariedad, como por el hecho de que sirvieron de base al más amplio relato del bellum Sertorianum de que disponemos y que será analizado más adelante, el producido por Plutarco de Queronea ${ }^{19}$. Pero no solo eso. Argumentaremos a continuación la opinión de que Salustio introduce por primera vez en su tratamiento del asunto una serie de temas que se transformarán en recurrentes en la producción posterior, mientras que su propia interpretación del carácter de Sertorio, llena de matices, debió convertirse en un punto de referencia obligado.

Como decimos, la concepción de la obra salustiana es singularmente compleja, convirtiéndose en un intrincado sistema alusivo ${ }^{20}$ que toma como referencia el entorno político del propio Salustio. De este modo, la narración de hechos pasados le permite desplegar sus propias opiniones, gustos, y consideraciones filosóficas. Esta concepción de la obra histórica determina la deformación de sus protagonistas, y Sertorio queda convertido en un maltratado por la fortuna, paralelo de un héroe trágico, un Odiseo arrastrado por los hados y dotado de una integridad digna de una suerte mejor que aquella que la fortuna le reserva.

Existen, sin embargo, en la obra de Plutarco, derivada al menos parcialmente de la narración salustiana ${ }^{21}$, algunos fragmentos de complicada interpretación (Plu. Sert. 10, 4-7), donde el biógrafo de Queronea parece estar casi justificando el deterioro moral de su héroe al final de su vida y que, para Rodríguez Horrillo ${ }^{22}$, pretenden refutar un desarrollo análogo presente en las Historias de Salustio. Según su interpretación, el caudillo romano habría padecido en dicha obra una evolución paralela a la que conocemos para otros personajes salustianos, como Yugurta o Catilina, igualmente dotados de una innegable virtus que, al corromperse por un

\footnotetext{
${ }_{18}^{18}$ Muntz, Charles, Diodorus Siculus and the World of the Late Roman Republic, Oxford y Nueva York, Oxford University Press, 2017, p. 236. Cf. también, sobre la herencia de la tradición de la monarquía helenística en Diodoro, el capítulo sexto (pp. 191-213).

${ }^{19}$ Sobre el uso de las Historias de Salustio por parte de Plutarco, $c f$. Scardigli, Barbara, "Considerazioni sulle fonti della biografia Plutarchea di Sertorio", en Studi italiani di Filologia classica, 43 (1971), pp. 33-64; Neira Jiménez, María Luz, "Aportación al estudio...” op. cit., pp. 202-204; Konrad, Christoph Frederick, Plutarch's Sertorius... op. cit., pp. LIII y ss.

${ }^{20}$ Katz, Barry Richard, “«Dolor», «invidia» and «misericordia» in Sallust”, en Acta Classica, 24 (1981), pp. 71-85; Katz, Barry Richard, "Sertorius, Caesar and Sallust", en Acta Antiqua, 29 (1981), pp. 285-314.

${ }^{21} \mathrm{Vid}$. nota 12.

${ }^{22}$ Rodríguez Horrillo, Miguel Ángel, "Plutarco transmisor de Salustio...” op. cit., pp. 272-275.
} 
ejercicio irresponsable de la misma, deja paso a los vicios de la ambitio. La idea es sumamente seductora, aun con las debidas precauciones que deben considerarse ${ }^{23}$.

Sin embargo, no puede negarse el contenido encomiástico de otros pasajes salustianos ( $c f$. I, 88; o I, 116 $)^{24}$. La explicación podría estar, precisamente, en el momento en que se produce la evolución en el carácter de Sertorio en la obra de Salustio. El arranque en la decadencia de su temperamento (II, 15) coincide exactamente con el momento en que Pompeyo entra en escena (II, 16-19), cerrando el camino a Italia y forzando un cambio en la estrategia sertoriana. Tal coincidencia no es casualidad: mientras Salustio percibe esta guerra como un enfrentamiento desesperado ante el ilegítimo régimen silano ${ }^{25}$, encaminado a lograr su deposición, otorga a Sertorio una confianza que se traduce en su positiva valoración. Este embrujo se rompe cuando el sabino se deja acorralar en una guerra imposible de exportar a Italia, momento a partir del cual se da por hecho que el motivo de su obstinación no es su amor a la patria, sino la ambición personal de un vulgar latro.

Por otro lado, encontramos en Salustio al responsable de introducir en la discusión del carácter de Sertorio una serie de temas que tendrán una peculiar recurrencia. Numerosas anécdotas sobre el personaje tienen en Salustio su fuente más probable ${ }^{26}$, y encontramos aceptable el considerar que en su visión como un jefe experto en celadas y en la guerra de guerrillas (I, 112; II, 29; II, 88) ha podido influir su proyección como un segundo Odiseo, alejado de la brutalidad y simpleza con que se caracteriza a su enemigo, Pompeyo, más próximo al carácter de Áyax Telamonio ${ }^{27}$. También en Salustio tenemos la primera mención conservada a las Islas Afortunadas como refugio ante la tormenta política en que se veía envuelto Sertorio ${ }^{28}$, un episodio que sirve para caracterizar al héroe positivamente, como carente de ambición. Por fin, en caso de aceptarse el modo en que proponemos que se opera el cambio en el carácter del Sertorio salustiano, surge de esta fuente la imagen de ese vir omnium atrocissimum, una vez que su carácter se ha corrompido. El relato de Salustio era suficientemente complejo como para proporcionar material tanto a los detractores como a los panegiristas del célebre general romano. Será la última vez en que nos encontremos ante un Sertorio "vivo", retratado por un hombre

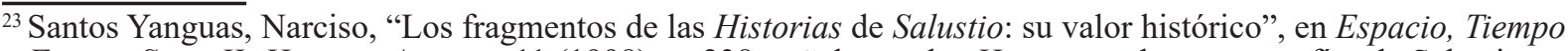
y Forma. Serie II: Historia Antigua, 11 (1998), p. 238, señala que las Historias y las monografías de Salustio no emplean el mismo marco ideológico ni los mismos procedimientos de creación de personajes, que aquí son simples figurantes y no motores de los acontecimientos.

${ }^{24}$ Todas las citas de las Historias siguen la numeración establecida por la editio de B. Maurenbrecher (1891), convertida ya en canónica.

${ }^{25}$ Es evidente el odio de Salustio hacia la dominación silana: quizá el fragmento más expresivo sea Hist. I, 44-51, donde, tras una dilatada narración de los horrores que siguieron a la segunda marcha sobre Roma de Sila, concluye en los siguientes términos: "Quo patefactum est rem publicam praedae, non libertati repetitam". Los discursos de Lépido y Licinio Macro (I, 77; III, 48), al margen de sus circunstancias concretas, son genuinas muestras de la ideología antisilana de Salustio: $c f$. Segura Ramos, Bartolomé, Introducción general a la obra de C. Salustio Crispo, Madrid, Gredos, 1997, p. 32 y nota 49.

${ }^{26}$ Neira Jiménez, María Luz, “Aportación al estudio...”op. cit., p. 198.

${ }^{27}$ Katz, Barry Richard, "Sertorius, Caesar and Sallust..." op. cit., pp. 300-301.

${ }^{28}$ McAlhany, Joseph, "Sertorius between Myth and History: the Isles of the Blessed episode in Sallust, Plutarch \& Horace", en The Classical Journal, vol. 112, 1 (2016), p. 70. DOI: 10.5184/classicalj.112.1.0057. "The Sertorius of Sallust's Histories [...] can only ponder an escape that does not exist as historical reality [...] and though he may have the desire to live in otio on some distant utopia, to escape the harsh reality enveloping him, he cannot".
} 
que, al margen de sus preferencias personales, está en situación de entender los presupuestos sociales y políticos latentes tras el episodio que protagonizó. A partir de aquí, alejándonos progresivamente del tiempo de Sertorio, nos encontraremos con autores que enfocan la historia de Roma desde posturas preconcebidas, como un proceso que conduce, según el punto de vista de cada cual, a un resultado concreto: en la concatenación de enfrentamientos civiles del siglo I a. C., Sertorio pasa a ser un accidente más, al que se enjuicia sin excesivo interés en profundizar en las causas o trasfondo reales de una epopeya deformada una y otra vez en función de quién la observe.

En su día, Schulten aceptó la tendencia 'pompeyana' de Livio (59 a. C.-17 d. C.) como un axioma, casi tomando al pie de la letra la jocosa acusación que, según Tácito, Augusto le habría lanzado como queja ante sus numerosas loas a Pompeyo (Tac. Ann. IV, 34). Pero el problema del posicionamiento político de Livio no es ni mucho menos tan sencillo: en general, encontramos en su obra una filosofía política contradictoria y que posiblemente se adapta a las circunstancias de la época ${ }^{29}$. En todo caso, resulta ilícito en el actual estado de la investigación reducir su obra a la condición de defensa del orden republicano atropellado por Augusto; casi tanto como buscar en sus líneas una mera plasmación de la reforma moral acaudillada por el princeps, aun cuando su propia concepción de la Historia como campo para la amplificación literaria, donde destacar ejemplos de virtudes y defectos útiles a sus contemporáneos (Liv. Praef. 9-10) sirviera a los propósitos moralizantes de aquél. El ideal liviano, y posiblemente eso a lo que Asinio Polión llamaba despreciativamente patavinitas (Quint. Inst. I 5, 56), podría haber sido el deseo de paz por encima del compromiso político, una suerte de inocencia política ajena a partidos y tomas de postura. Aplicado a Sertorio, esto debe haberse traducido en una visión que lo condena por agitador y responsable de una guerra civil, sin que ello suponga inmediatamente una visión adversa, como Schulten supuso en su día ${ }^{30}$. En todo caso, la tradición liviana llegada hasta nosotros es muy complicada y, si puntualmente se denuesta la actitud del sabino para con sus propios partidarios (Per. 92), lo cierto es que el extenso fragmento 22 según la numeración de Wissenborn-Müller presenta un hombre de tintes más bien heroicos (fr. 22, 1), clemente con los vencidos (fr. 22, 2) y centrado en organizar a los reunidos bajo su mando mediante asambleas antes que mediante amenazas o coacciones (fr. 22, 3-7). Dudamos mucho que a la vista de los textos aludidos pueda seguirse sosteniendo que Livio enarboló la más rancia bandera del antisertorianismo ${ }^{31}$.

\footnotetext{
$\overline{{ }^{29} \text { El problema del }}$ posicionamiento político de Livio se discute en varias contribuciones del reciente Companion dedicado al patavino: Mineo, Bernard (ed.), A companion to Livy, Malden, Chichester y Oxford, Wiley-Blackwell, 2015. Para Paul-Marius Martin, Livio exterioriza un convencimiento republicano a través de sus reservas frente a la figura de César; sin embargo, para Bernard Mineo, la filosofía política de Livio se acomodaba bien a un gobierno autocrático basado en la proclamación de la virtud. Martin, Paul-Marius, "Livy's Narrative of the Regal Period: Structure and Ideology", en Mineo, Bernard (ed.), A companion... op. cit., pp. 268-269; y Mineo, Bernard, "Livy's Political and Moral Values and the Principate", en Mineo, Bernard (ed.), A companion... op. cit., pp. 130-131.

${ }^{30}$ Schulten, Adolf, Sertorius... op. cit., p. 62: “... le transforman Livio [y Apiano], sin apelación, en un tirano y un sádico...".

${ }^{31}$ La bibliografía sobre la obra de Livio es ingente, especialmente por lo que se refiere a su relación con Augusto y con el régimen monárquico que éste encarnaba. Pueden consultarse Chaplin, Jane Dunbar, Livy's Exemplary
} 
Otra cosa muy diferente es que el relato de Livio haya servido de base fundamental, si bien no única, a diversos epítomes e historias redactadas por autores tardíos, destacando las obras de Floro (prob. s. II d. C.), y Orosio (s. IV d. C.), aun con las consabidas discrepancias en cuanto a qué porcentaje de lo que podemos leer en ambos procede del historiador de Patavium ${ }^{32}$. Da la sensación, por los datos que transmite, de que Floro ha consultado una fuente antisertoriana (Flor. II, 10 [III, 22]), pero como Neira afirma con buen juicio ${ }^{33}$, los datos positivos que entrevera en su relato con un interés retórico apuntan a un uso al menos secundario de una fuente de signo contrario. Del mismo modo, Orosio parece haberse enfrentado a versiones contradictorias que lo empujan a la manipulación y a la inserción de juicios personales (Oros. $\mathrm{V}, 24,16 ; \mathrm{V}, 19,9 ; \mathrm{V}, 21,4 ; \mathrm{V}, 23,2)$ para sostener su conservadora y cristiana visión del fluir de la Historia, caótica sucesión de desgracias hasta el advenimiento de Cristo ${ }^{34}$. Que Livio haya sido la base fundamental de ambos relatos no lo convierte en un antisertoriano, pues una de las características más destacadas en la obra de estos historiadores tardíos es el carácter selectivo de sus epítomes o historias, que acomodan a sus objetivos las informaciones de que disponen. Ambos han contribuido a crear, posiblemente a partir de Livio sin desdeñar otras fuentes, un Sertorio más cruel y negativo.

Resultan sin duda de utilidad las reflexiones de John Alexander Lobur sobre la relación existente entre ideología y poder para acercarnos a las visiones del episodio sertoriano que se esbozan en Veleyo Patérculo y, particularmente, en Valerio Máximo. Tradicionalmente, se ha apuntado a una actitud represiva frente a la escritura de la Historia en época tiberiana, de la que sería muestra el proceso incoado a instancias de Sejano a Cremucio Cordo, autor de unos controvertidos Anales incómodos al poder imperial (Tac. Ann. IV, 34-35; Suet. Tib., 3-4). La inmediata deducción era la de que solamente el escritor domesticado podía desarrollar su trabajo sin despertar los recelos del poder político ${ }^{35}$. Esta visión, sin embargo, resulta problemática por las dudas que despierta la imagen despótica y resentida de Tiberio en que se basa, forjada en los fuegos de una tradición senatorial adversa (Suet. Tib. 41-67; Cass. Dio. LVIII, ff. 1-3). A su vez, y adentrándonos en el juicio sobre el período de guerras civiles que nos interesa, el criterio de valoración con que operan Patérculo y Máximo es ante todo el de "respeto a la tradición”, y así,

\footnotetext{
History, Oxford, Oxford University Press, 2000, especialmente pp. 168-196; Mineo, Bernard, Tite-Live et l'histoire de Rome, París, Klincksieck, 2006; o, en castellano, Sierra, Ángel, Tito Livio, Madrid, Gredos, 2012, pp. 55-61.

${ }^{32}$ Son ilustrativas al respecto las introducciones a las ediciones de ambos en la Biblioteca Clásica Gredos. Sobre Floro, Hinojo Andrés, Gregorio e Isabel Moreno Ferrero, Introducción general a la obra de L. Floro, Madrid, Gredos, 2000, especialmente pp. 9-10 acerca de la elaboración retórica de Floro en torno a la historia de Roma como un proceso que culmina bajo Augusto, y pp. 30-42 sobre sus fuentes y el uso de las mismas. Respecto a Orosio, Sánchez Salor, Eustaquio, Introducción general a la obra de Paulo Orosio, Madrid, Gredos, 1982, apunta con claridad que su obra es una apología del cristianismo como alivio a los males que han precedido a su advenimiento (pp. 19-24), donde se recoge una cadena de calamidades (pp. 41-49).

${ }^{33}$ Neira Jiménez, María Luz, “Aportación al estudio...” op. cit., pp. 204-205.

${ }^{34}$ González Fernández, Rafael y Miguel Pablo Sancho Gómez, "La figura de Sertorio en la Hispania del siglo v. Una perspectiva tardía durante el tiempo de las invasiones bárbaras", en Studia Historica. Historia Antigua, 28 (2010), pp. 135-153.

${ }^{35}$ López Moreda, Santiago et al., Introducción general a la obra de Valerio Máximo, Madrid, Gredos, 2003, p. 13. Sobre la relación entre escritura de la historia y poder en tiempos de Tiberio, $c f$. pp. 12-14 y nota 13.
} 
las virtudes de personajes como Catón de Útica o Cn. Pompeyo son curiosamente celebradas (Vel. Pat. II, 29; II, 35; Val. Max. II, 10, 7-8; V, 9-10). Encontramos acertada la idea de que los escritores de época tiberiana plasman por escrito en sus obras el discurso social de consensus y concordia sobre "qué significaba ser romano" que la generación anterior había alcanzado espontáneamente, que relativizaba algunos contenidos del debate político republicano y alzaba los conceptos de pax y la tranquillitas a un lugar preeminente ${ }^{36}$. Desde esta perspectiva, no es necesaria la coacción permanente del régimen imperial para que los protagonistas del turbulento pasado republicano queden artificialmente divididos entre "romanos" (todos aquellos que garantizan la estabilidad del sistema con sus acciones) y "enemigos" (los demás, agrupados en una masa informe). Las referencias de Veleyo Patérculo a Sertorio se mueven en este nivel de análisis; y así, Sertorio resulta ser el único responsable del estallido de una guerra (Vel. Pat. II 25, 3) que se concibe en términos equívocos, al representarse como un enfrentamiento entre "romanos" e "hispanos" $(90,3)$. No nos atreveríamos a afirmar con Neira ${ }^{37}$ que la visión negativa de Perperna (II, 30, 1-2) manifieste el uso de una fuente no antisertoriana: el rechazo del recurso al magnicidio encaja perfectamente en el universo intelectual de Patérculo (tanto por su tendencia conservadora como por las resonancias cesarianas que el asesinato a manos de sus allegados podían despertar: II, 46, 3; II, 56, 3 y ss.).

Las mismas consideraciones de partida sirven a la hora de comprender la imagen de Sertorio que nos brinda Valerio Máximo. Erraríamos si intentásemos analizar los fragmentos relevantes para nuestros intereses de forma aislada, sin comprender su lugar general en una obra que pretende ofrecer estabilidad al Imperio mediante la recopilación enciclopédica de ejemplos históricos. Los hechos memorables de grandes hombres del pasado son juzgados y valorados en función de su adecuación a las virtudes cardinales del tiempo de Tiberio, perdiendo en el proceso todo atisbo de significado histórico: sus motivos, ransformados en material retórico y didáctico, pasan a recrearse de un modo casi ucrónico donde poco importan las motivaciones de sus protagonistas. Así, Sertorio es sumariamente descrito como "dotado por igual de fuerza física y cordura" (Val. Max. VII, 3, 6), pero su retrato, en general y más allá de referencias puntuales a la lealtad que despertó entre los calagurritanos (VII, 6 ext. 3) o a su cierva blanca (Val Max. Paris, I, 2, 4), carece de peso específico ${ }^{38}$. La nómina de episodios recogidos por Valerio Máximo, por lo demás, no hace sino confirmar nuestra visión de la obra salustiana como la referencia básica contemplada por los autores clásicos a la hora de tratar el conflicto

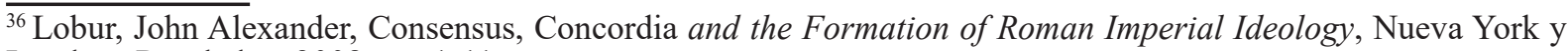
Londres, Routledge, 2008, pp. 1-11.

${ }^{37}$ Neira Jiménez, María Luz, “Aportación al estudio...” op. cit., p. 196.

${ }^{38}$ Ya Carney destacó la condición inconsistente del retrato de Mario en Valerio Máximo. Carney, Thomas Francis,

"The Picture of Marius in Valerius Maximus", en Rheinisches Museum für Philologie, 105 (1962), pp. 294-295.

"Valerius'depiction of Marius' character is marred by much inconsistency, as might be expected from an excerptor who has to make facts fit into certain predetermined categories" (p. 333); sin embargo, Carney probablemente yerra al atribuir a Máximo un objetivo ("to integrate a mass of unconnected references in a unified and accessible body of original material", pp. 291-292) que seguramente nunca estuvo en su mente, siendo la concepción de su obra esencialmente retórica.
} 
sertoriano, pues como demostró María Luz Neira, la práctica totalidad de las estampas que nos encontramos en los Hechos y dichos memorables tienen un antecedente directo en las Historias de Salustio ${ }^{39}$.

El siguiente retrato de Sertorio en que deberíamos fijarnos, siquiera brevemente, es el que nos encontramos en la biografía de Plutarco (c. 50-c. 120). Ya hemos señalado anteriormente algunas peculiaridades del mismo (vid. supra, p. 36), que deriva en buena medida del personaje salustiano. Sin embargo, parece haber motivos para considerar la existencia de una fuente alternativa, que el biógrafo consulta cuando los intereses narrativos ${ }^{40}$ de su obra aconsejan separarse en algún sentido del relato que le sirve de guía ${ }^{41}$. Su principal interés es describir el carácter de los grandes hombres del pasado con acuerdo a su mundo ideológico y filosófico, convirtiéndolos en modelos de conducta para sus contemporáneos. Como consecuencia, somete a las fuentes de que dispone a una selección centrada en la transmisión de aquellas anécdotas que muestran la naturaleza de sus protagonistas, a menudo, más patente en los pequeños hechos cotidianos que en los grandes episodios (Plu. Aem. I, 1-5) ${ }^{42}$. La Vida de Sertorio es, precisamente, uno de los productos plutarqueos más marcados por la ejemplaridad y la reelaboración literaria ${ }^{43}$. El autor de Queronea escoge a sus protagonistas con un discurso comparativo en mente, que ejecuta mediante una selección interesada de episodios que permiten la reflexión moral en aquellos términos en que el escritor había planteado su obra: en este caso, el fundamento de la $\sigma \dot{\gamma} \gamma \kappa \rho \imath \sigma \iota \varsigma$ es, explícitamente, el poderío que extiende la Fortuna, la $\tau \dot{\chi} \chi \eta$, sobre los asuntos de los hombres (Plu. Sert. I, 1-2; I, 10) ${ }^{44}$. Este interés caracterológico es la explicación del tono anecdótico que impregna el relato plutarqueo, carente de un armazón cronológico sólido ${ }^{45}$ y que, en definitiva, debe ser utilizado con suma precaución. Es interesante destacar, por otro lado, la cantidad de elementos cínico-estoicos que concurren sobre el ideal monarca en que, por momentos, se torna el Sertorio de Plutarco ${ }^{46}$; algo que ya nos habíamos encontrado en Diodoro y que refuerza la hipótesis de encontrar en Posidonio la "fuente griega" de la Vida de Sertorio (vid. notas 16 y 39 ).

\footnotetext{
${ }^{39}$ Neira Jiménez, María Luz, “Aportación al estudio...” op. cit., pp. 196-198.

${ }^{40}$ No hemos de olvidar, a pesar de que sea un lugar común, que Plutarco no es un historiador, sino un biógrafo, como él mismo se esforzó en dejar claro en su Alejandro (Plu. Alex. I).

${ }^{41}$ Sobre las controvertidas fuentes de Plutarco, $c f$. la bibliografía citada en la nota 19. Ya Scardigli insistió en la posibilidad de que la famosa fuente griega fuese Posidonio, idea que ha subrayado más recientemente y desde otros presupuestos García Morá, Félix, "Entre la leyenda y la realidad: la cierva de Sertorio", en VVAA, In memoriam J. Cabrera Moreno, Granada, Servicio de Publicaciones de la Universidad de Granada, 1993, pp. 175-178.

${ }^{42}$ Lesky, Albin, Historia de la Literatura griega. Vol II, Madrid, Gredos, 2010, pp. 473-475.

${ }^{43}$ Konrad, Christoph Frederick, Plutarch's Sertorius... op. cit., pp. XXVI-XXVII y XXX-XXXIX.

${ }^{44}$ Tatum, Jeffrey W., "Why Parallel Lives?", en Numble, Noreen (ed.), Plutarch's Lives. Parallelism and Purpose, Rosehill Terrace, The Classical Press of Wales, 2010, pp. 1-22. DOI: https://doi.org/10.2307/j.ctvvnbtz.6. Este autor considera que una suerte de agonismo cultural entre griegos y romanos es el fundamento de las comparaciones de Plutarco, sin aportar gran cosa a nivel literario a la obra. En contraste con esta opinión encontramos la de Christoph Konrad, para quien la synkrisis tiende a concentrar las diferencias entre caracteres para lograr el efecto pedagógico buscado mediante la abstracción de vicios y virtudes. Konrad, Christoph F. Plutarch 's Sertorius... op. cit., p. XXXI.

${ }^{45}$ Salinas de Frías, Manuel, "Reflexiones sobre la guerra de Sertorio..." op. cit., pp. 23-24.

${ }^{46}$ García Moreno, Luis Alberto, "Paradoxography and Political Ideals in Plutarch's Life of Sertorius", en Stadter, Philip A. (ed.), Plutarch and the Historical Tradition, Londres y Nueva York, Routledge, pp. 132-158.
} 
Por fin, culminamos este breve repaso sobre las fuentes clásicas con una referencia a Apiano (c. 95-c. 160). La concepción histórica de este autor hace de la monarquía el punto de llegada de los conflictos civiles desatados en tiempo de los Graco, exaltando la época imperial como culmen del poderío romano y de la concordia imperante dentro del mismo. Su narración de las guerras civiles se convierte así en una sucesión de horrores y actitudes crueles, ejemplificadas en las figuras de los personajes que han ostentado el poder y han desgarrado a la República en sus luchas ${ }^{47}$. Estas constantes explican muchas de las características que se perciben en el tratamiento de Apiano sobre la figura y hechos de Sertorio (B.C. I, 108-114): sucesión de actos violentos y bárbaros (109, destrucción de Lauro; asesinato de toda una cohorte de romanos; 112, masacre de 3000 calagurritanos); comportamiento deshonroso impropio de un romano (108, toma de Suesa con perfidia; 110, dependencia bárbara de la seguridad que da la superstición; o 113, entrega a la bebida y la molicie) y narración apegada a los movimientos de Pompeyo, antes que a los de un Sertorio que no pasa de ser un actor secundario en la crisis de la República a ojos de Apiano (así, solo a partir de 109, donde se produce la llegada de Pompeyo a la Península, el relato adopta la forma analística). Gabba consideraba que la disposición de los hechos se corresponde con la que debieron presentar en el relato de Livio, y que es lícito suponer una directa dependencia respecto a este, conclusión que sin embargo resulta "muy arriesgada" para Neira ante el estado de conservación de los fragmentos livianos ${ }^{48}$. En todo caso, nuevamente debemos ser cautos a la hora de utilizar a Apiano como fuente, en su caso, por el hecho de que fabrica un Sertorio violento, manipulador y supersticioso, con lo cual queda configurada, ahora sí, una polarización entre dos relatos, uno encomiástico y otro difamatorio, que pervivirá en las reinterpretaciones posteriores de Sertorio.

\section{A modo de conclusión: los estudios sertorianos hoy. Perspectivas de futuro}

Su figura, como hemos pretendido hacer patente, ha sido objeto de una continuada reelaboración, sometida al vaivén ideológico de los tiempos. Nuestra imagen actual se ha

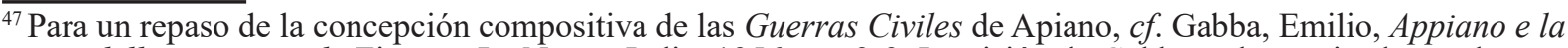
storia delle guerre civili, Firenze, La Nuova Italia, 1956, pp. 3-9. La visión de Gabba se ha matizado en algunos sentidos, y, si bien no se cuestiona la lealtad de Apiano hacia el Imperio romano ni el hecho de que es éste el único protagonista de su obra (cf., sin ir más lejos, Hisp. 101), sí se ha cuestionado la visión excesivamente plana (y negativa) de la obra de un historiador que sobrepasa la mera condición de recopilador. $C f$. Gómez Espelosín, Francisco Javier, "Contradicciones y conflictos de identidad en Apiano", en Gerión, vol. 27, 1 (2009), pp. 231250; Welch, Kathryn (ed.), Appian's Roman History: Empire and Civil War. Roman culture in an age of civil war, Swansea, Classical Press of Wales, 2015. DOI: https://doi.org/10.2307/j.ctt1ws7x7f.10.

${ }^{48}$ Gabba, Emilio, Appiano e la storia ... op. cit., pp. 99-101; contra, Neira Jiménez, María Luz, “Aportación al estudio..." op. cit., p. 206. Según esta, con buen criterio, Apiano demuestra conocimiento de la obra de Plutarco, que emplea con objetivos polémicos. Sobre las fuentes de Apiano, $c f$. las aportaciones de Jonathan Price y Richard Westall en el mencionado volumen coordinado por Welch, Kathryn (ed.), Appian's Roman History... op. cit.
} 
urdido con estos mimbres, reinterpretados sin embargo una vez más en los fundamentales trabajos que firmaron a principios del siglo xx A. Schulten y H. Berve ${ }^{49}$, de signos radicalmente opuestos. Ambos proyectaron sobre el pasado sus visiones del presente; y si bien no es ninguna sorpresa comprobar que la Historia Antigua juega un papel en la construcción (invención, diría Benedict Anderson) de identidades nacionales ${ }^{50}$, sí sorprende el completo triunfo de una de las dos tradiciones. Donde el Sertorio de Berve quedó reducido a la marginalidad especializada, el de Schulten se ha transformado en referencia obligada. La visión más esencialista y belicista del pasado ha mostrado una singular estabilidad, posiblemente relacionada con la atractiva combinación de grandes personajes y sobrecogedores episodios de violencia, lealtad y resistencia que ofrecía el ciclo sertoriano. Hoy, aparece aún empañado por una bruma mítica que sigue sin remitir $^{51}$. Y ello a pesar de los esfuerzos de la investigación actual por desplazar el foco sobre los fundamentales e ignorados tiempos que preceden a la aparición de Sertorio y que sientan las bases sobre las que ha de analizarse su episodio ${ }^{52}$; sin olvidar por supuesto la dimensión más puramente social e ideológica del mismo. Es esta, precisamente, la línea en que se ha de incidir en los próximos años. El conflicto sertoriano ha sido analizado en demasiadas ocasiones como un cuerpo extraño dentro del proceso general hacia la integración que se percibe en los años previos en la Hispania romana, cuando lo que en realidad deberíamos plantearnos es qué lugar ocupa dentro del mismo. Integrar en un discurso unitario los materiales arqueológicos y las referencias textuales, y sobre todo, hacerlo sin adoptar perspectivas excluyentes que ignoren a los diversos actores que toman parte en él, es el desafío al que se enfrenta la investigación.

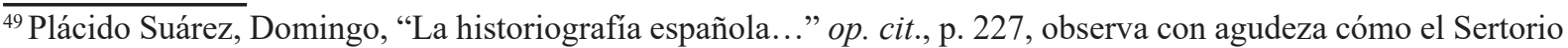
de Berve es un rebelde envuelto en un ilegítimo conflicto con el poder establecido, mientras que el de Schulten es un héroe romántico tardío, en palabras de Plácido, "prefascista". Es significativo, en este sentido, que Berve siga los relatos de Diodoro, Livio y Apiano, mientras que Schulten confía ciegamente en la obra de Plutarco.

${ }^{50}$ Son fundamentales en este sentido los trabajos de Wulff, Fernando, Las esencias patrias. Historiografia e Historia Antigua en la construcción de la identidad española (siglos XVI-XX), Barcelona, Crítica, 2003; Wulff, Fernando, "Adolf Schulten. Historia antigua, arqueología y racismo en medio siglo de historia europea" [estudio introductorio a la reedición de A. Schulten, Historia de Numancia, 1945], Pamplona, Urgoiti Editores, pp. IXCCLVI. Wulff aprecia cómo los tópicos clásicos sobre los pobladores prerromanos de la Península, tanto como los posteriores resultados de la "dominación romana", ofrecían una base inmejorable sobre la que edificar un discurso nacionalista centralista (Wulff, Fernando, Las esencias patrias... op. cit., p. 31). Nos limitamos a remitir al lector que quiera comprobar la certeza de esta afirmación al siguiente trabajo: Ramos y Loscertales, José María, "La devotio ibérica”, en Anuario de Historia del Derecho español, 1 (1924), pp. 7-26.

${ }^{51}$ Cf. Plácido Suárez, Domingo, "La historiografía española..." op. cit., p. 228. Hay, sin embargo, fundados motivos para la esperanza: como apunta Scardigli, Barbara, "Trent'anni di studi sertoriani”, en Urso, Gianpaolo (ed.), Hispania terris omnibus felicior. Premesse ed esiti di un processo di integrazione. Atti del convegno internazionale, Pisa, Edizioni ETS, 2002, pp.143-160, en el curso de los últimos tres decenios se ha operado un recambio generacional renovador en el seno de los "studi sertoriani"; e igualmente, circunstancias de la investigación tras la muerte de Franco han abierto nuevas perspectivas (cf. especialmente p. 147: "Soprattutto però si è cercato di inserire la vicenda di Sertorio in un contesto più ampio [...] Perciò si è prestata più attenzione [...] alla presenza di vari strati sociali in Spagna, valutando su quali presumibilmente Sertorio potè contare..."). ${ }^{52}$ Roldán Hervás, José Manuel, "De Numancia a Sertorio. Problemas de la romanización de la península Ibérica en vísperas de las guerras civiles", en Eck, Werner et al. (eds.), Studien zur antiken Sozialgeschichte. Festschrift Friedrich Vittinghoff, Colonia y Viena, Böhlau Verlag, 1980, pp.157-178; Pina Polo, Francisco, "Hispania y su conquista en los avatares de la República tardía”, en Andreu Pintado, Javier et al. (eds.), Hispaniae. Las provincias hispanas en el mundo romano. Recull de les ponencies de le III reunió de Tudela sobre Historia Antigua, Tarragona, Institut Català d'Arqueologia Clàssica, 2009, pp. 224-236; Sánchez Moreno, Eduardo, "Las guerras celtibéricolusitanas (114-93 a. C.) y su dimensión geopolítica", en Principal Ponce, Jordi et al. (eds.), Roma en la Península Ibérica presertoriana. Escenarios de implantación militar provincial, Barcelona, Publicacions i Edicions de la Universitat de Barcelona, 2017, pp. 59-78.
} 
En cierta medida, las limitaciones que advertimos en buena parte de las visiones generadas hasta el momento presente sobre el bellum sertorianum vienen generadas por las lecturas escasamente introspectivas de unas fuentes que se contemplan ante todo como transmisoras de datos concretos, pero que pueden revelar, defendemos, lecturas más plurales y complejas, siempre y cuando se indague debidamente tras su superficie "histórica” (¿mítica?, ¿literaria?). Este camino ha de permitir avanzar hacia la mejor intelección de la época, dejando de lado las nociones de romanización y barbarie, sustituidas por un acercamiento más multifactorial y poliédrico. Atrás queda la imagen romántica de Sertorio, tanto como la reacción que despertó y que hacía casi obligado hablar del episodio sertoriano con insistencia en su condición de bellum internum que, siendo cierta, no debería impedir una exploración profunda de los intereses de los actores locales implicados.

Las fuentes que han de acompañarnos en este camino no quedan ya determinadas por una engañosa pretensión de veracidad. Pretender seleccionar el relato "más veraz" es olvidar que cada uno de ellos, como hemos pretendido hacer patente, tiene un discurso propio y selecciona o reelabora los datos de que dispone con acuerdo al mismo. Acercarse a las fuentes con esta idea en mente garantiza un uso más equilibrado de las noticias que nos ofrecen, en las cuales residen las claves para aportar nuestra propia contribución a la construcción permanente de "una" historia. Muchos de los datos que pueden analizarse desde esta reflexión de fuentes toman sentido en el contexto en que los crearon sus autores, cuyas perspectivas en perpetuo cambio pueden, como hemos visto, obrar cambios profundos e impredecibles sobre la tradición. La atención puede recaer sobre informaciones juzgadas irrelevantes previamente; los hechos pueden quedar engarzados en una concatenación espuria o cobrar un significado nuevo carente de adecuación con su sentido original. Nada de ello puede ser estudiado, insistimos, sin una adecuada comprensión de las ideologías y relaciones textuales que alimentan cada relato. 